\title{
Colorimetric measurements as control elements in wood conservation status
}

\section{Ovidia Soto-Martín}

Faculty of Fine Arts, Universidad de La Laguna, Santa Cruz de Tenerife. Spain

osotomar@ull.edu.es

\begin{abstract}
This paper is a methodological proposal for the study of altarpieces on wooden supports. The process was implemented to study the altarpiece of San Antonio de Padua in Garachico, Tenerife. For this, we conducted a review of key aspects appropriate to the discipline of wood identification carried out by macroscopic examination and for the characterization of the status of deterioration by colorimetric analysis. For the evaluation of the wood conservation status, the samples were subjected for the first time to colorimetric measurement. As a result we have created an online database to provide information for conservation professionals permitting them to design a proposal for preventive conservation and intervention individually for each object.
\end{abstract}

\section{Keywords}

Colour

Colorimetry

Wood

Preventive conservation

Geolocation

Restoration

\section{Colorimetria como análise de controlo do estado da madeira}

\section{Resumo}

Este trabalho é uma proposta metodológica para o estudo de retábulos em suportes de madeira. O processo foi implementado para estudar o retábulo de San Antonio de Pádua em Garachico, Tenerife. Para isso, foi realizada uma revisão dos aspectos-chave adequados para a disciplina de identificação de madeira realizada por meios macroscópicos e para a caracterização do grau de deterioração por análise colorimétrica. Para a avaliação do estado de conservação da madeira, as amostras foram submetidas pela primeira vez a análise colorimétrica. Como resultado, criámos um banco de dados on-line para fornecer informações para os profissionais de conservação que Ihes permitam apresentar uma proposta de conservação preventiva e de intervenção de forma individual para cada objecto.

\section{Palavras-chave}

Cor

Colorimetria

Madeira

Conservação preventiva

Geolocalização

Restauro 


\section{Introduction}

Up to the present time studies and interventions that are carried out within the field of Heritage Conservation and Restoration in the Canary Islands make use of infrastructure and specialists who are outside the island territory. Due to the insular nature, budgets and waiting time increase significantly and in many cases causes the impossibility of a good and complete performance of the work, inasmuch as the analysis are the foundations for establishing further intervention.

This study aims to provide professional access to basic information collected in a digitized database of the type of wood to be analysed and extrapolated to other future studies. This catalogue also contains colorimetric analysis results, specially the patterns of variation in colour and brightness, which will be the control points for good preventive conservation.

The knowledge of the chromaticity coordinates of the wood will play a fundamental role not only in the conservation of the original colour after cleaning, reinstatement or any other intervention, but also in establishing a reference to perform periodic measurements, with the aim to follow the degree and chromatic deterioration rate and therefore, to investigate its causes.

To carry out this proposal, we began with macroscopic wood identification. Then, the samples were subjected for the first time to colorimetric measurement. As a result we have created an online database to provide information for conservation professionals about the geographical location of the cultural property studied.

\section{Methodology}

The CIE, or Commission Internationale de l'Eclairage (translated as the International Commission on Illumination), is the body responsible for international recommendations for photometry and colorimetry. In 1931 the CIE standardized colour order systems by specifying the light source (or illuminants), the observer and the methodology used to derive values for describing colour.

The colour space used here was the perceptual or uniform CIELAB, recommended by CIE (Commission Internationale de l'Éclairage) for studies of secondary sources, whose lightness $\left(L^{*}\right)$ is related to $Y$ from system CIEYxy, both going from 0 (black) to 100 (white), and whose colour coordinates $a^{*}$ and $b^{*}$ define the degree of pitch (from green to red, $a^{*}$, and from blue to yellow, $b^{*}$ ).

The key tool in colour measurement is the spectrophotometer, photometric device that measures spectral transmittance, spectral reflectance or relative spectral emittance. Its information regarding the spectral composition, is not only necessary to solve many problems related to the colour (the degree of metamerism - a phenomenon exhibited by a pair of colours that match under one or more sets of illuminants, be they real or calculated, but not under all illuminants - , the nature of
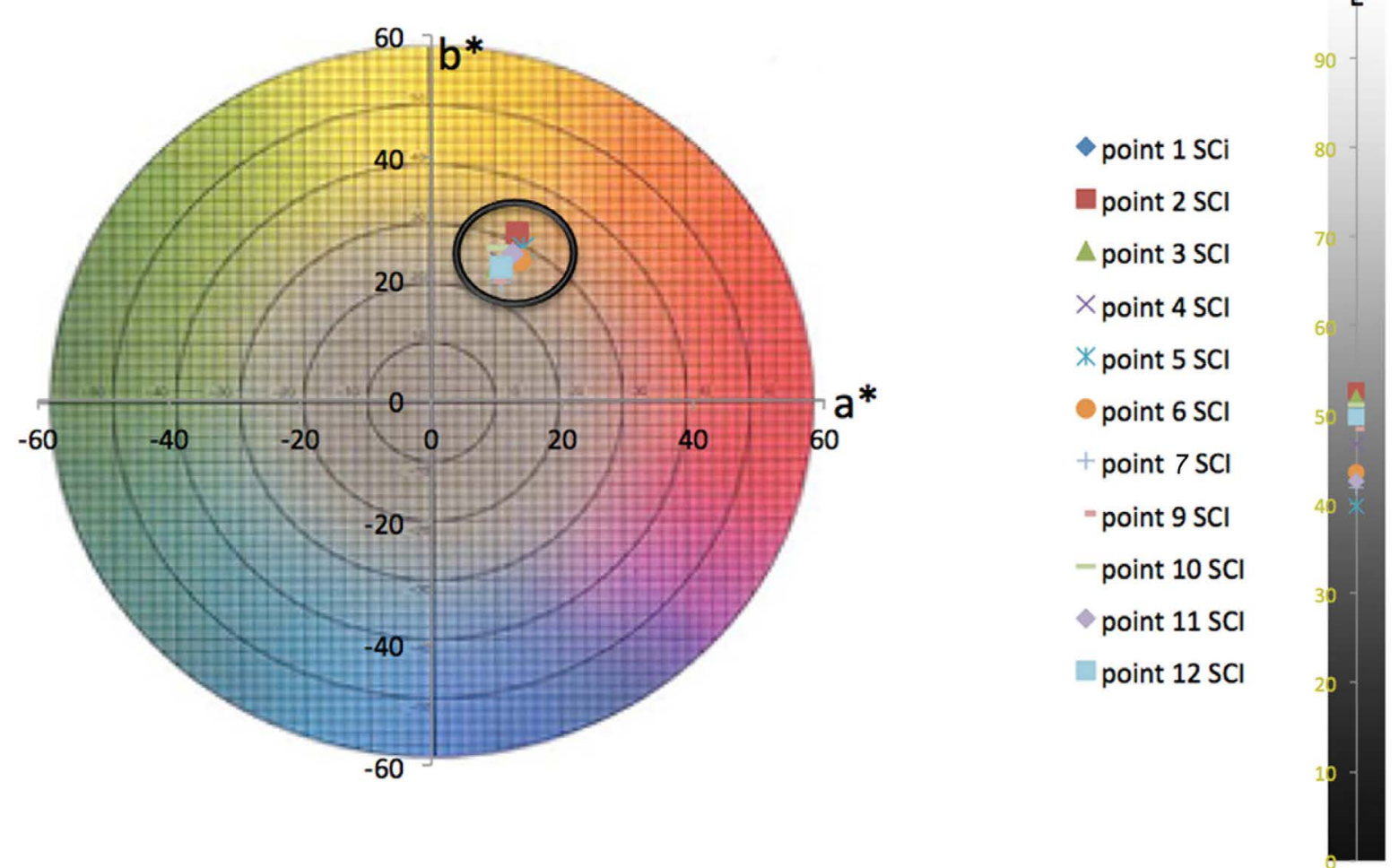

Figure 1. Representation of the CIELAB measurements in the chromaticity diagram. 
Table 1

CIELAB data obtained.

\begin{tabular}{|c|c|c|c|c|c|c|c|c|}
\hline Sample & Section & Name & $L^{*}(\mathrm{SCI})$ & $L^{*}(\mathrm{SCE})$ & $a^{*}(\mathrm{SCI})$ & $a^{*}(\mathrm{SCE})$ & $b^{*}(\mathrm{SCI})$ & $b^{*}(\mathrm{SCE})$ \\
\hline \multirow[t]{3}{*}{ Sample 4} & Transversal & Point 1 & 50.0880 & 50.3202 & 12.5757 & 12.4786 & 24.4417 & 24.5935 \\
\hline & Tangential & Point 2 & 52.7751 & 52.6670 & 13.1310 & 13.0517 & 27.4193 & 27.5547 \\
\hline & Radial & Point 3 & 51.9541 & 52.0105 & 9.8061 & 9.7295 & 22.2097 & 22.3461 \\
\hline \multirow[t]{3}{*}{ Sample 3} & Transversal & Point 4 & 46.7352 & 46.8134 & 10.6720 & 10.6209 & 22.5444 & 22.7269 \\
\hline & Tangential & Point 5 & 39.8523 & 39.8650 & 14.0451 & 14.0394 & 24.9348 & 25.1736 \\
\hline & Radial & Point 6 & 43.6439 & 43.7945 & 13.5464 & 13.4589 & 23.0342 & 23.1039 \\
\hline \multirow[t]{2}{*}{ Sample 2} & Transversal & Point 7 & 41.9336 & 42.1134 & 10.5637 & 10.5154 & 19.4754 & 19.6479 \\
\hline & Radial & Point 9 & 48.4014 & 48.2435 & 9.7271 & 9.7099 & 19.6980 & 19.9186 \\
\hline \multirow[t]{3}{*}{ Sample 1} & Transversal & Point 10 & 51.1794 & 51.3031 & 10.1166 & 10.0364 & 24.9296 & 25.0750 \\
\hline & Tangential & Point 11 & 42.6305 & 42.7030 & 12.4997 & 12.4582 & 24.1448 & 24.3573 \\
\hline & Radial & Point 12 & 49.7986 & 49.8015 & 10.6653 & 10.6231 & 21.9345 & 22.2132 \\
\hline
\end{tabular}

the pigment, the protection and conservation techniques, etc.), but also linking the results with the CIE standard specifications.

Minolta Spectrophotometer CM-2600D has been used for the colorimetric study in measurement conditions $\mathrm{SCE} / 100$ (specular reflectance excluded) and SCI/100 (specular reflectance included), D65 illuminant (the CIE standard illuminant that represents a colour temperature of $6504 \mathrm{~K}$, which is the colour temperature most widely used in graphic arts industry), $10^{\circ}$ observer and small measurement area.

\section{Anatomical wood comparison}

The anatomical structure of the wood is the same since its formation in the trunk and is retained until it is degraded. It can be approached with a $\times 10$ lens or an optical microscope.

Identification of the woods by anatomical comparison is not free of problems. In fact, presents gender and generic subgroup limitations, as in the case of oak (Quercus sp.). In such cases it is very rarely to identify the species with only anatomical description, so that any information on its chorology, origin, common name, country or geographic region is also important for the determination.

Another limitation is that the species belonging to the same gender are often hardly distinguishable [1].

For this study, we delimited the search to a specific number of woods used in Cultural Heritage objects and discard hundreds of others that are present in nature. We obtained four samples to work with.

\section{Wood colorimetry}

There are many studies about the colour of the wood collected in various colour atlas, but all are based either on a single area of the sample (sapwood, heartwood...) or in a single tree species.

In recent years there has been progress in this field, analysing the colour changes due to artificial drying, assessing the visual appearance of species for solid uses or determining the optical properties more desirable for pulp and paper [2].

The optical properties of the wood can be modified according to the site, the clone, the tree and the position within the individual, so it is essential to know these patterns of variation.

The most complete and meaningful way to characterize the visual appearance of a material is to use three-dimensional colour data, but within these, the parameter $L$ or Lightness (Figure 1), is the more simple and satisfactory way to specify the endpoint of an objective, therefore both the chromatic and non-chromatic values (Table 1) are necessary to characterize the colour changes [3].

\section{Results}

The parameter $L^{*}$ or clarity was set as the most important criterion, especially when carrying out control over future photo-degradation (Figure 1). Similar studies (2) have measured the colour in 97 species to determine their suitability for use, establishing relationships between parameters of the system CIELAB and obtaining mean values of $L^{*}$ that varied within a broader range than the data of the chromaticity coordinates $a^{*}$ and $b^{*}$. According to this, future changes in this parameter will alert us about changes in climate conditions and obviously in wood conservation status.

In the same way, spectral reflectance curves indicate the features present at the time of measurement in terms 
of brightness and hue of the wood. Based on these, future changes in the depth and shape of the reflectance spectrum could be interpreted as changes in the brightness and hue of the wood respectively.

With all the information obtained we have created an online database (Figure 2) to provide information for conservation professionals about the geographical location of the cultural property studied. We used the open web app Google Maps which allowed us to create our own paths and slides according to the results and the data we had collected and to upload them into an open database like Google Earth.

Finally, we can conclude this phase of the research affirming that when there is no data available to establish comparative studies, merely external data as hue and chroma are not enough for analysis. That means we need a period of time to enrol the professionals and request them to improve and complete the colorimetric database.

\section{Conclusions}

With the application of the proposed methodology, we will be able to manage relevant data about the amount and type of wood used in the Cultural Heritage objects on the island of Tenerife, in addition to information about their conservation status thanks to the new colorimetric control points.

The database will collect the information about the location, environmental conditions such as altitude, temperature, relative humidity and bioclimatic belt. Furthermore, the colorimetric analysis will be included for the first time with the "control points". This control points can serve as a standard for monitoring the successive processes of restoration with a georeferenced database (that is, geolocated) in geographical space and chronologically. Thereby, environmental changes in bioclimatic belt will affect colorimetric parameters of wood, allowing professionals to design a proposal for preventive conservation and intervention, individually for each object.

The database contributes to apply global trends of information and communications technology in the new information society and knowledge, which helps social, cultural and economic support for sustainable development.

Because the study is still in progress, we must wait a certain period of time to consider the effects of its application in the professional field as well as the process of training and technical information appropriate to monitor cultural property listed in the catalogue.

Furthermore, this work began with limited objectives that are expanding day by day. As a future project, is planned to include in the database environmental parameters of the area surrounding cultural goods, moisture content in the wood and everything that would show that the methodology presented here is well suited for application in the field of conservation and restoration of heritage.

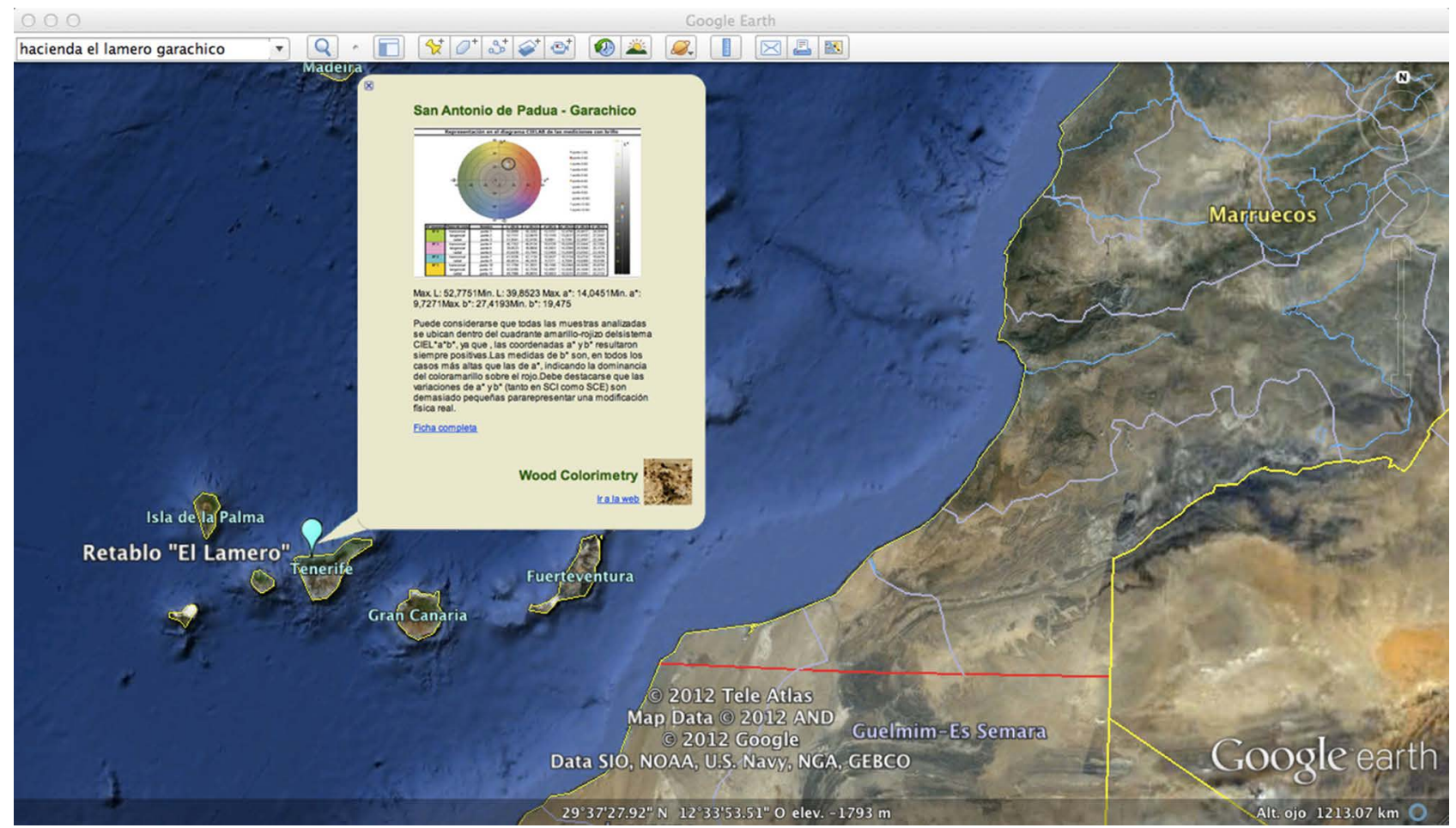

Figure 2. Georeferenced database screenshot. 


\section{References}

1 García Esteban, L.; Guindeo Casasús, A., Anatomía de las Maderas Frondosas Españolas, Asociación de Investigación Técnica de las Industrias de la Madera y Corcho, Madrid (1990).

2 Nishino, Y.; Janin, G.; Chanson, B.; Détienne, P. ; Gril, J.; Thibaut, B., 'Colorimetry of wood specimens from French Guiana', Journal of Wood Science 44(1) (1998) 3-8, doi:10.1007/BF00521867.

3 Popson, S. J.; Malthouse, D. D.; Robertson, P. C., 'Applying brightness, whiteness and color measurements to color removal', TAPPI Journal 80(9) (1996) 137-147.
Received: 15 December 2014

Revised: 2 February 2015

Accepted: 5 February 2015

Online: 9 February 2015

This work is licensed under the Creative Commons Attribution-NonCommercial-NoDerivs 3.0 Unported License. To view a copy of this license, visit http://creativecommons.org/licenses/by-nc-nd/3.0/deed.pt. 